\title{
Coupled Multiple Musculo-Neurovascular Variations in Same Upper Limb. A Case Report and Clinical Significances
}

\author{
Múltiples Variaciones Músculo-Neurovasculares Conectados en el \\ Mismo Miembro Superior. Reporte de un Caso y Significados Clínicos
}

Olutayo Ariyo*

\begin{abstract}
ARIYO, O. Coupled multiple musculo-neurovascular variations in same upper limb. A case report and clinical significances. Int. J. Morphol., 33(4):1406-1410, 2015.

SUMMARY: Variants of the median nerve, extra forearm flexor muscles heads are relationships of the persistent median artery (PMA) that have been extensively reported. We report the findings of a PMA (diam. $3.25 \mathrm{~mm}$ ), a pierced median nerve, and accessory heads of the flexor digitorum profundus (FDP) and flexor policis longus (FPL) muscles coexisting with a brachioradial artery (BRA) (diam.1.8mm) in the left upper limb of a 65 year-old male cadaver. The median nerve provided a ring for the passage of the PMA about the junction of the proximal and middle thirds of the forearm. Both accessory muscles were placed anterior to the ulnar artery, with the brachioradial artery coursing superficially in the brachium and antebrachium. The notable diameter of the PMA may be etiological in the causation of a carpal tunnel syndrome, while the hypoplastic BRA may pose some challenges in its selection as good conduit for catheterization and other surgical interventions like CABG in the upper limb. Additional clinical interest include the possible reduction in blood supply to the hand from the compressive effect of the 2 accessory muscles on the ulnar artery and possible inadvertent drug injection due to the superficial placement of the brachioradial artery close to veins.
\end{abstract}

KEY WORDS: Persistent median artery; Pierced median nerve; Extra forearm muscle bellies; brachioradial artery; Carpal tunnel syndrome.

\section{INTRODUCTION}

The brachioradial artery (BR) and the PMA are embryonic arterial patterns which fail to regress from the vascular-skeletal development of the arterial blood supply to the upper limb, a development which starts as a capillary network and undergoes enlargement and differentiation in a proximal to distal fashion in parallel with differentiation of the surrounding mesenchyme. It is suggested that the persistence, enlargements and differentiation of the initial capillary network which would normally remain in a capillary state or even regress, gives rise to arterial variations of the definitive arterial pattern rather than sprouting of aberrant vessels (Singer, 1933). Embryologically, the median artery is the dominant blood supply to the hand, occurring as a transitional vessel representing the arterial axis during early embryonic life. The median artery normally regresses in the second month of intrauterine life (DeVriese, 1902; Muller, 1903) existing in two varieties, antebrachial and palmar types respectively. When the median artery persists in adult life, based on its vascular territory, it is classified as either palmar or antebrachial. The palmar type is large, long and reaches the palm, representing the embryonic type, which contrasts with the antebrachial type which is slender, short and ends before reaching the wrist (Salmon, 1933; Valdecasas-Huelin et al., 1979). The PMA has a range of incidence from 17-20\% (Kopuz et al., 1997; Rodriquez-Niedenführ et al., 1993). RodriquezNiedenführ et al., also reported that the palmar pattern is more frequent in females than in males [1.3 (ratio)1] occurring unilaterally more than bilateral [4( ratio) 1$]$ and slightly more frequent on the right hand on the left [1.1 (ratio)1]. Also reported that the palmar pattern ended as the 1st, 2nd, 1st and common digital arteries [65\%] or joined the superficial palmar arch. The occurrence of the PMA with unusual division of the median nerve has been reported by several authors (Chalmers, 1978; Toranto, 1988). The case of a ring formation encircling the PMA just below the inferior border of the pronator teres has also been reported (Adachi, 1928). Brachioradial arteries are variant radial arteries originating proximal to the elbow, with $76 \%$ occurrence of cases arising in the brachium, compared to $24 \%$ from the axillary artery (RodriquezNiedenführ et al.). The incidence of occurrence of the BRA is $14 \%$ and the artery is one of the several arteries in the upper limb topographically located along the arm and forearm. Other vessels of similar topography include the brachioulnar artery $(4.7 \%)$ and brachiomedian artery $(0.7 \%)$ respectively. 
Several radiologic and anatomical studies have reported of the existence of accessory muscles of the forearm, more in the extensor than in the flexor compartment and most of the time are asymptomatic. These coupled multiple musculo-neurovascular variations occurring in same upper limb is very rare and they carry multiple clinical implications.

\section{CASE REPORT}

The case being reported was observed after careful review of partially dissected upper limb by Medical students SKMC at Jefferson Medical College in Philadelphia. An

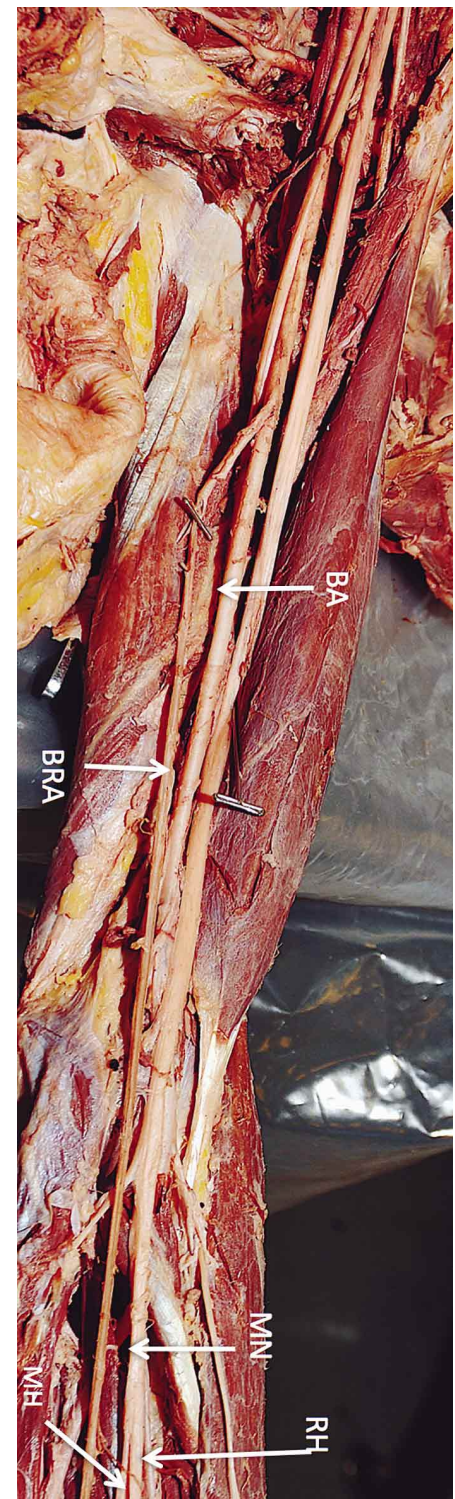

Fig. 1. Image shows a brachioradial artery originating from the upper $1 / 3$ of the arm. At the cubital fossa, the median nerve can be observed into two, and providing a passage for the persistent median artery. $\mathrm{BA}=$ brachial artery, $\mathrm{BRA}=$ brachioradial artery, $\mathrm{MN}=$ median artery, $\mathrm{RH}=$ radial head of splitting $\mathrm{MN}, \mathrm{MH}=$ medial head of splitting MN.

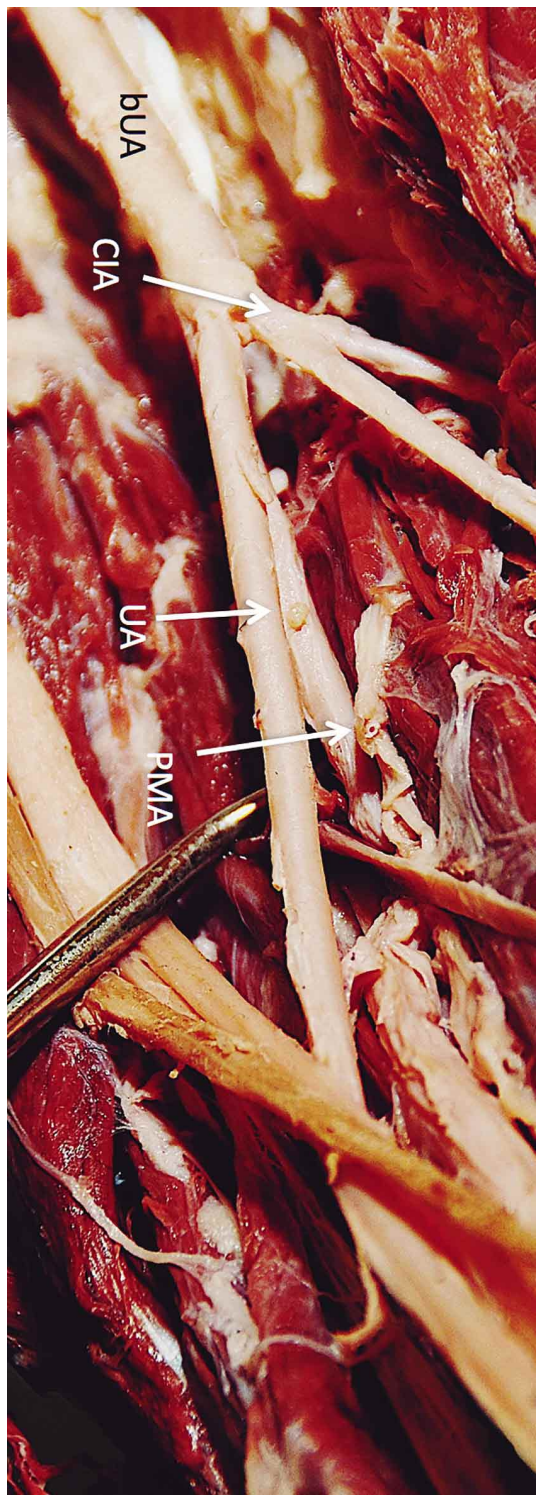

Fig. 2. A bifurcating ulnar artery yields a trunk, the common interosseous artery and the main ulnar artery which gave off the persistent median artery between the artery and caudal angle of the common interosseous artery. bUA= bifurcating ulnar artery, CIA = common interosseous artery, $\mathrm{UA}=$ ulnar artery, $\mathrm{PMA}=$ persistent median artery.

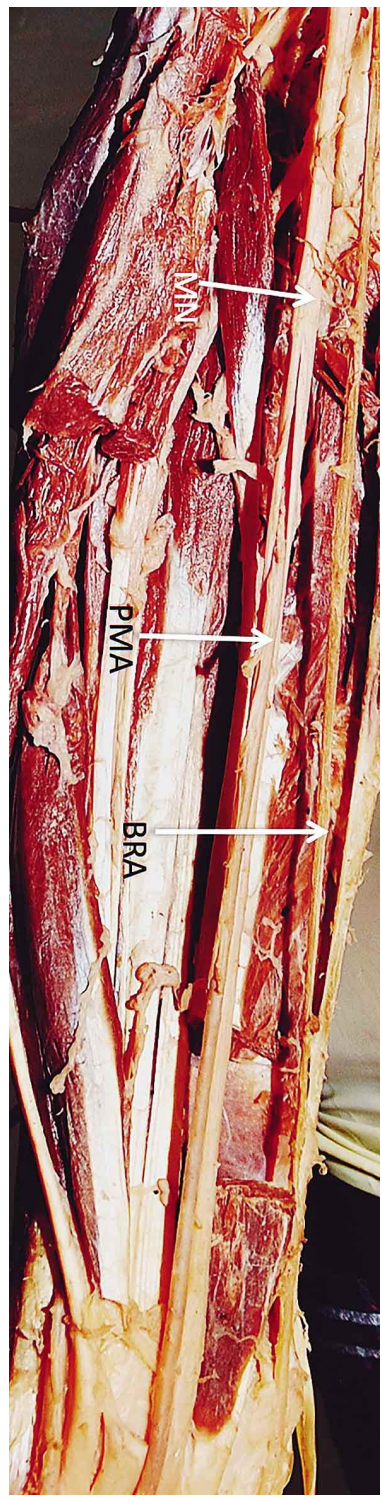

Fig. 3. The image shows the persistent median artery escaping through a passage provided by a splitting median nerve. The notable size of the persistence median nerve can be compared to the hypoplastic brachioradial artery. $\mathrm{MN}=$ median nerve, $\mathrm{PMA}=$ persistent median artery, $\mathrm{BRA}=$ brachioradial artery. 


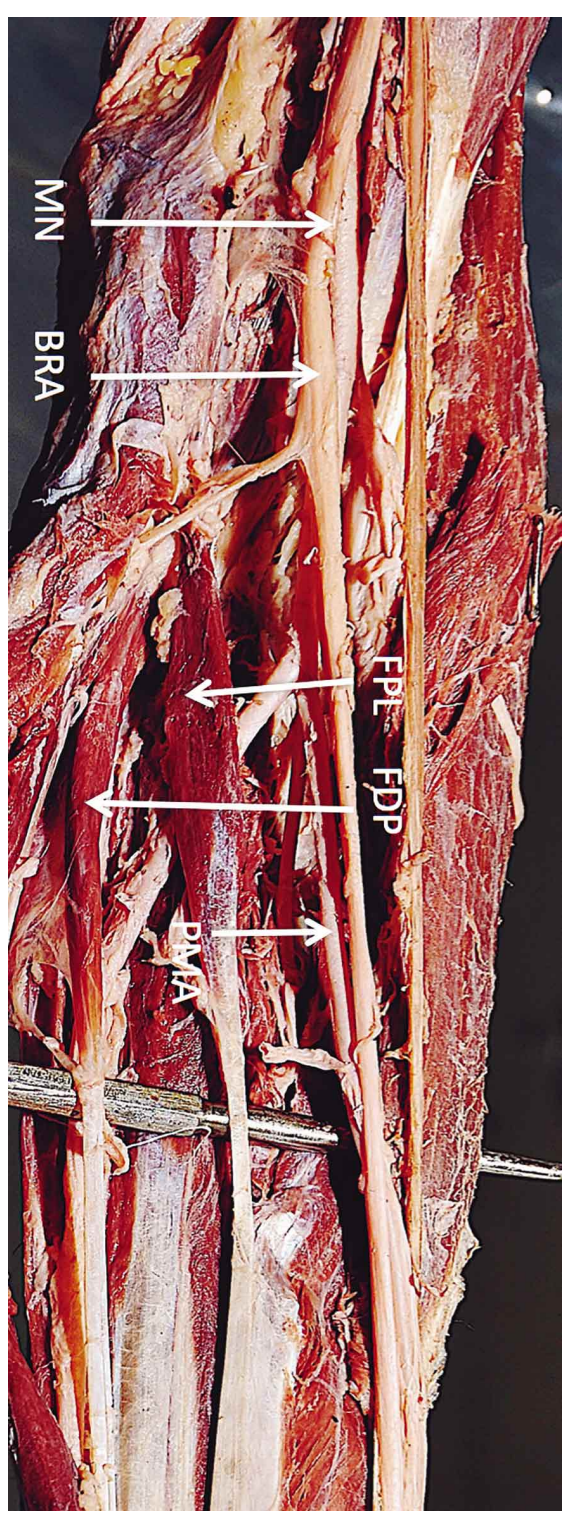

Fig. 4. Image shows the accessory muscle heads of the flexor pollicis longus, superior to the flexor digitorum longus. FPL= flexor pollicis longus muscle, FDP= Flexor digitorum profundus muscle.

hypoplastic brachioradial artery (BRA) was observed arising from the medial side of the BA in the proximal 1/3rd and runs a superficial course both in the arm and later in the forearm (Fig. 1). The BRA coursed superficially in the brachium inclining lateral-ward at about the level of the cubital fossa and eventually placed in the usual location travelled by the radial artery (Fig. 1). The reported is hypoplastic, (diam. $<1.8 \mathrm{~mm}$ ), which contrasts with the notable size of the PMA (Diam.= $3.25 \mathrm{~mm}$ ) (Figs. 1 and 2). The BRA ran anterior to both the brachial artery and $\mathrm{MN}$ crossing diagonally in the cubital fossa. In the forearm, the BRA travelled distally coursing superficial in the region normally travelled by the radial artery and contributed to the formation of the superficial palmar arch in the hand (Fig. 3).

The brachial artery continued as the ulnar, gave rise independently to the common interosseous artery (CIA) followed by the PMA of a notable size $(3.25 \mathrm{~mm})$ arising in the caudal angle between the CIA and the ulnar artery. This artery coursed inferiorly and was initially placed posterior to the MN. At about the junction of the proximal and middle thirds of the forearm, the artery pierced the MN postero-anteriorly and becoming medially placed to the nerve, a relationship maintained both in the distal forearm as well as in the carpal tunnel, posterior to the flexor retinaculum (Fig. 3).

The PMA contributed primarily to the palmar arterial anastomosis by supplying blood to the $2^{\text {nd }}$ and $3^{\text {rd }}$ palmar digits. We did not observe any communications between the BRA and the brachio-ulno-interosseous vessel. There was no observed anastomosis between the BRA and the PMA until when the PMA supplemented the palmar arterial arch. There was no evidence of thrombosis or calcification in the PMA.

We also encountered 2 extra muscle bellies, a superiorly placed FPL and an inferiorly placed FDP (Fig. 4). Both muscle bellies were found placed anterior to the ulnar artery, the right upper limb arterial pattern was found normal and there were no duplication of the extra-muscle bellies in the contralateral forearm.

\section{DISCUSSION}

There are several reports in surgical, radiologic and cadaveric studies of the PMA co-existing with MN. This relationship was found to be much more than the existence of the MN being pierced by the PMA. A bifid MN and a PMA are anatomic variations that have been reported extensively in the surgical literature (Stansic et al., 1995), a relationship considered etiologic in the causation of the CTS (Chalmers).

Other documented anomalies related to motor branch of the $\mathrm{MN}$ besides the BMN include ulnar and anterior take off of the motor branch, transligamentous and subligamentous course of the motor branch (Lindley \& Kleneirt, 2004). Our reported PMA originates in the caudal angle between the CIA and the ulnar artery. Other sources of origins of the PMA include the ulnar artery, the anterior interosseous artery and the posterior interosseous artery (Quain, 1844; Adachi). Rodriquez-Niedenführ et al., reported that the most common origin of the artery is the caudal angle between the common interosseous artery (CIA) and the ulnar artery. Our reported PMA shares same origin with the latter.

Association between the PMA and extra bellies of some forearm muscles had also been reported. Rodriquez-Niedenführ et al., reported finding extra bellies of FDP and that of the FPL in $20 \%$ of cases studied. The BRA is a radial 
artery arising proximally above the elbow and they tend to form a second artery with the brachial artery in the brachium and usually are placed superficially in the arm and forearm, where they may be ligated inadvertently or involved in trauma leading to severe bleeding. The superficial placement of the BRA makes it more vulnerable to intra-arterial injection of drugs due to its proximity with superficial veins. Possible intra-arterial injection of drugs due to proximity of normal vein puncture sites has been reported (Cohen, 1948). A contrast dye injected distal to the origin of the BRA would lead to possible arterographic misinterpretations (Uglietta \& Kadir, 1989).

A relationship that was not reported in most previous studies of the PMA is the association between the artery an accessory muscle heads of FPL and FDP (Gantzer's muscles) until reported by Jones et al. (1997). Rodriquez-Niedenführ et al., reported that this association presented in $20 \%$, with the artery anterior to them in $83 \%$ of cases and posterior in $17 \%$.

In the reported case the 2 accessory muscle bellies were observed to be anterior to the ulnar artery and this could result in possible compression of the artery by the muscles bellies, leading to a compromised blood supply to hand structures.

Piercing of the MN has been implicated in the causation of the pronator syndrome (Jones \& Ming, 1988), but McCormack et al. (1953) and Keen (1961) mentioned this as a casual finding with an incidence range from 1123\% (McCormack et al.; Keen), but a higher incidence rate of $41 \%$ of cases was reported by Rodriquez-Niedenführ et al., who also reported that all piercing of the MN were always associated with the palmar variety. Rodriquez-Niedenführ et al., reported finding the PMA anterior to the accessory muscle heads in $23 \%$ of cases and in $77 \%$ of the cases, the artery was posterior. However, both muscle bellies in our report were placed anterior to the ulnar artery, a relationship that can possibly result in compression effect with compromised vascular supply to some hand structures.

The notable size of the PMA may serve to augment blood supply to hand structures especially with a hypoplastic BRA. In addition, the hypoplastic nature of our radial artery (diameter $1.8 \mathrm{~mm}$ ) will make this a poor choice as a conduit for $\mathrm{CABG}$ where vessels of $2.5 \mathrm{~mm}$ or greater diameter are required.

A relationship between the size of the diameter of the PMA and the causation of the CTS has been reported (Bafred et al., 1985). A range from $0.7 \mathrm{~mm}$ to $2.7 \mathrm{~mm}$ had been reported for the arterial diameter of the PMA (Gassner et al., 2002). Bafred et al., reported that the PMA with external diameter greater than $2 \mathrm{~mm}$ can cause a CTS. With a $3.25 \mathrm{~mm}$ diameter reported of our PMA, it is easy to predict the likelihood of this causing a CTS. The latter would easily be achieved either by a compression effect on the nerve or in limiting the osteofascial space in the tunnel.

Other morphological variants of the PMA that may cause a CTS include thrombosis (Beran et al., 1997), calcification of the artery in the carpal tunnel (Dickinson \& Kleinert, 1978), but were found absent in our case. A PMA may play some useful role in palmar circulation in case the radial or ulnar artery is missing.

Pre-operative Doppler and ultrasonography may reveal the presence of a PMA and the existence of a variant PMA, which would enhance better planning and reduction of iatrogenic complications. Nurses and other Healthprofessionals are advised to palpate the forearm region for pulsation before setting up an IV or cannulating a vessel especially at the elbow region, so as to avoid inadvertent drug administration into a superficial artery mimicking a superficial vein, which carries with it attendant dangers of ischemic necrosis, gangrene and possibly limb loss.

\section{ACKNOWLEDGEMENTS}

Thanks to my wife, Olubunmi for understanding the late hours kept at work, Authorities at Pathology, Anatomy and Cell Biology at SKMC at Thomas Jefferson University, Profs. Peiper and Schmidt for an enabling scholarship environment. To our cadaver, immense thanks for making contributions to knowledge even in death.

ARIYO, O. Múltiples variaciones músculo-neurovasculares conectados en el mismo miembro superior. Reporte de un caso y significados clínicos. Int. J. Morphol., 33(4):1406-1410, 2015.

RESUMEN: Variantes del nervio mediano y cabezas adicionales de los músculos flexores del antebrazo, se relacionan con la arteria mediana persistente (AMP). Presentamos los resultados de una AMP (diámetro 3,25 mm), un nervio mediano pinzado y cabezas accesorias de los músculos flexor profundo de los dedos (FPD) y flexor largo del pulgar (FLP) que coexisten con una arteria braquiorradial (ABR) (diámetro 1,8 $\mathrm{mm}$ ) en el miembro superior izquierdo de un cadáver de sexo masculino de 65 años. El nervio mediano proporciona un anillo para el paso de la AMP sobre la unión de los tercios proximal y medio del antebrazo. Ambos músculos accesorios se colocaron por delante de la arteria ulnar, con la arteria braquiorradial ubicada superficialmente en el brazo y en el antebrazo. El diámetro notable de la AMP puede ser la 
causa del síndrome del túnel carpiano, mientras que la ABR hipoplásica puede plantear algunos desafíos en su selección como buen conducto para la cateterización y otras intervenciones quirúrgicas como la cirugía de revascularización coronaria a partir del miembro superior. De interés clínico se considera la posible reducción en el suministro de sangre debido a la compresión de los 2 músculos accesorios a la arteria ulnar y la posible inyección fallida de drogas debido a la ubicación superficial de la arteria braquiorradial, cercana a las venas.

PALABRAS CLAVE: Arteria mediana persistente; Nervio mediano perforado; Músculos accesorios del antebrazo; Arteria braquiorradial; Síndrome del túnel carpiano.

\section{REFERENCES}

Adachi, B. Das Arteriensystem der Japaner. Bände I. Kyoto, Universität zu Kyoto, 1928. pp.364-72.

Barfred, T.; Højlund, A. P. \& Bertheussen, K. Median artery in carpal tunnel syndrome. J. Hand Surg. Am., 10(6 Pt. 1):864-7, 1985.

Beran, S. J.; Friedman, R. M. \& Kassir, M. Recurrent digital ischemia due to thrombosis of the persistent median artery. Plast. Reconstr. Surg., 99(4):1169-71, 1997.

Chalmers, J. Unusual causes of peripheral nerve compression. Hand, 10(2):168-75, 1978.

Cohen, S. M. Accidental intra-arterial injection of drugs. Lancet, 2(6524):409-17, 1948.

DeVriese, B. Recherches sur l'évolution des vaisseaux sanguins des membres chez l' homme. Arch. Biol., 18:665-730, 1902.

Dickinson, J. C. \& Kleinert, J. M. Acute carpal-tunnel syndrome caused by a calcified median artery. A case report. J. Bone Joint Surg. Am., 73(4):610-1, 1991.

Gassner, E. M.; Schocke, M.; Peer, S.; Schwabegger, A.; Jaschke, W. \& Bodner, G. Persistent median artery in the carpal tunnel: color Doppler ultrasonographic findings. J. Ultrasound Med., 21(4):455-61, 2002.

Jones, N. F. \& Ming, N. L. Persistent median artery as a cause of pronator syndrome. J. Hand Surg. Am., 13(5):728-32, 1988.

Jones, M.; Abrahams, P. H.; Sañudo, J. R. \& Campillo, M. Incidence and morphology of accessory heads of flexor pollicis longus and flexor digitorum profundus (Gantzer's muscles). J. Anat., 191(Pt. 3):451-5, 1997.

Keen, J. A. A study of the arterial variations in the limbs, with special reference to symmetry of vascular patterns. Am. J. Anat., 108:245-61, 1961.
Kopuz, C.; Baris, S. \& Gulman, B. A further morphological study of the persistent median artery in neonatal cadavers. Surg. Radiol. Anat., 19(6):403-6, 1997.

Lindley, S. G. \& Kleinert, J. M. Prevalence of anatomic variations encountered in elective carpal tunnel release. J. Hand. Surg. Am., 28(5):849-55, 2004.

McCormack, L. J.; Cauldwell, E. W. \& Anson, B. J. Brachial and antebrachial arterial patterns; a study of 750 extremities. Surg. Gynecol. Obstet., 96(1):43-54, 1953.

Müller, E. Beitrage zur Morphologie des Gefäßsystems. I. Die Armarterien des Menschen. Anatomische Hefte., 22:377-575, 1903.

Quain, R. The Anatomy of the Arteries of the Human Body. London, Taylor \& Walton, 1844.

Rodriquez-Niedenführ, M.; Sañudo, J. R.; Vázquez, T.; Nearn, L.; Logan, B. \& Parkin, I. Median artery revisited. J. Anat., 195(Pt. 1):57-63, 1993.

Salmon, M. Arteres des Muscles des Membres et du Tronc. Paris, Masson, 1933.

Singer, E. Embryological pattern of median artery persisting in the arteries of the arm. Anat. Rec., 55:403-9, 1933.

Stancic, M. F.; Eskinja, N. \& Stosic, A. Anatomical variations of the median nerve in the carpal tunnel. Int. Orthop., 19(1):30-4, 1995.

Toranto, I. R. Aneurysm of the median artery causing recurrent carpal tunnel syndrome and anatomic review. Plast. Reconstr. Surg., 84(3):510-2, 1988.

Uglietta, J. P. \& Kadir, S. Arteriographic study of variant arterial anatomy of the upper extremities. Cardiovasc. Intervent. Radiol., 12(3):145-8, 1989.

Valdecasas-Huelin, J. G.; Barreiro, F. J. \& Campelo-Barcia, E. Etude radio-anatomique de l'artère médiane. Acta Anat. (Basel), 105:250-5, 1979.

Correspondence to:

Olutayo Ariyo MBBS, MBA

Pathology, Anatomy and Cell Biology

Thomas Jefferson Medical College of Thomas Jefferson

University

Rm $263 \mathrm{~F}, \mathrm{JAH}$,

1020 Locust Street

Philadelphia PA 19050

USA

Email: olutayo.ariyo@jefferson.edu

Received: 12-05-2015

Accepted: 20-08-2015 